PIASSA, Felipe José e DIAS, Bruno Smolarek. Influências pós-positivistas ao novo direito constitucional e o fenômeno da constitucionalização do direito. Revista Eletrônica Direito e Política, Programa de Pós-Graduação Stricto Sensu em Ciência Jurídica da UNIVALI, Itajaí, v.10, n.3, $2^{\circ}$ quadrimestre de 2015. Disponível em: www.univali.br/direitoepolitica - ISSN 1980-7791.

\title{
INFLUÊNCIAS PÓS-POSITIVISTAS AO NOVO DIREITO CONSTITUCIONAL E O FENÔMENO DA CONSTITUCIONALIZAÇÃO DO DIREITO
}

\author{
POST POSITIVE INFLUENCES TO THE NEOCONSTITUTIONAL LAW AND \\ THE PHENOMENON OF LAWS CONSTITUTIONALIZATION
}

\author{
Felipe José Piassa ${ }^{1}$ \\ Bruno Smolarek Dias ${ }^{2}$
}

SUMÁRIO: Introdução; 1 . A ciência jurídica e as suas eras; 2 . Um novo panorama para o direito constitucional; Considerações finais; Referências das Fontes Citadas.

\section{RESUMO}

O objetivo do presente trabalho é abordar, com base em pesquisa bibliográfica, as transformações históricas que levaram a mudança dos paradigmas do Direito, o que resultou no surgimento de um novo Direito Constitucional, importando em uma nova hermenêutica constitucional e impondo força normativa à Constituição. Como consequência desse processo, verificamos o surgimento do fenômeno denominado constitucionalização do Direito e da efetividade do direito constitucional, aquele correspondente a uma irradiação de valores abrigados nos princípios e regras da Constituição por todo o ordenamento jurídico, resultando na aplicação direta da Lei Maior e na interpretação das normas infraconstitucionais conforme a Carta Fundamental. Concluímos que o Direito, a fim de acompanhar as mutações das relações sociais e pessoais, exige mudanças que não conseguem ser acompanhadas com a edição de leis e decretos, tornando fundamental o papel do Poder Judiciário na interpretação constitucional e das demais normas sob a luz da Constituição Federal, com vistas a assegurar a

\footnotetext{
${ }^{1}$ Acadêmico do Curso de Direito da Universidade Paranaense - UNIPAR, Unidade Universitária de Francisco Beltrão - PR. E-mail: felipe_piassa@hotmail.com.

2 Doutor em Ciências Jurídicas pela Universidade do Vale do Itajaí - UNIVALI. Mestre em Direito pela Pontifícia Universidade Católica do Paraná - PUC-PR. Professor do Programa de Mestrado em Direito Processual e Cidadania da Universidade Paranaense Unipar. E-mail: professorbruno@unipar.br
} 
PIASSA, Felipe José e DIAS, Bruno Smolarek. Influências pós-positivistas ao novo direito constitucional e o fenômeno da constitucionalização do direito. Revista Eletrônica Direito e Política, Programa de Pós-Graduação Stricto Sensu em Ciência Jurídica da UNIVALI, Itajaí, v.10, n.3, $2^{\circ}$ quadrimestre de 2015. Disponível em: www.univali.br/direitoepolitica - ISSN 1980-7791.

melhor prestação jurisdicional e, principalmente, a dignidade da pessoa humana e os direitos fundamentais.

PALAVRAS-ChaVe: pós-positivismo; direito constitucional; neoconstitucionalismo; constitucionalização do direito.

\section{ABSTRACT}

This article has the objective, based in bibliographical research, the historical changes that led to the alteration of Laws paradigms, those that seeded the appearance of a neoconstitutional law, a new hermeneutics and the imposition of the constitutional norms. As a result of this process it is seen the insurgence of a phenomenon known as the constitutionalization of Law and the effectiveness in constitutional norms, that correspond to a value that irradiates from the principles and norms in the constitution through the entire jurisprudence. This results in the direct application of the Magna Charta and the interpretation of all laws by the boundaries set by the Constitution. It concludes that the norm, with the objective to set changes in social and personal relations, in foremost occasions has a time gap, arriving too late for so. And the use of constitutional law is a landmark to warranty the best adjudication and foremost the human dignity and human rights.

KEY WORDS: postpositivism; Constitutional Law; neoconstitucionalism; Laws constitutionalization

\section{INTRODUÇÃO}

A borboleta, meticulosa e vagarosamente começa a romper o casulo que a envolvia. Aos poucos sobressaem as suas asas, o restante do seu corpo. O vento a toca pela primeira vez. Sem demora, o inseto lança-se, enfim, ao novo e desconhecido mundo.

Malgrado a metáfora, o Direito pátrio também encerra outro de seus ciclos.

As mudanças, que se apresentam concomitantemente como causa e também consequência do que ora se apresenta, são as protagonistas deste singelo trabalho. A sociedade e suas crenças, ideologias e culturas modificam-se quase que tão rápidas quanto a velocidade da luz (por óbvio, figurativamente). Pela ótica de Zygmunt Bauman, axiomas e postulados dantes sólidos deram azo a uma "modernidade líquida" (expressão que é título de uma das suas mais 
PIASSA, Felipe José e DIAS, Bruno Smolarek. Influências pós-positivistas ao novo direito constitucional e o fenômeno da constitucionalização do direito. Revista Eletrônica Direito e Política, Programa de Pós-Graduação Stricto Sensu em Ciência Jurídica da UNIVALI, Itajaí, v.10, n.3, $2^{\circ}$ quadrimestre de 2015. Disponível em: www.univali.br/direitoepolitica - ISSN 1980-7791.

importantes obras), ante as suas constantes mutações ${ }^{3}$. O que é hoje, não era ontem e certamente não será amanhã (agora sim, literalmente). As organizações sociais não se mantêm por muito tempo, dissolvem-se até mais rápido do que se constroem.

O Direito, por sua vez, não pode quedar-se inerte a tais transformações. E de fato não o faz. O cenário jurídico também respira ares de mudança.

O positivismo jurídico há tempos já não se mostra adequado e eficiente aos problemas do Direito. Todavia, seria inviável retornar aos postulados jusnaturalistas, eis que notadamente seria um verdadeiro retrocesso, não se olvidando, ainda, de sua superação histórica.

Desse modo, com a superação história do jusnaturalismo e o fracasso político do positivismo jurídico, emergiram novas reflexões e questionamentos acerca do Direito. Estas reflexões - que fazem jus ao brocardo "antes tarde do que nunca" resultaram no movimento conhecido como pós-positivismo e, consequentemente deram origem a chamada nova hermenêutica constitucional, e a teoria dos direitos fundamentais ${ }^{4}$, à força normativa da Constituiçãa ${ }^{5}$, dentre outros efeitos/fenômenos que serão melhor aprofundados.

O artigo que se segue tem por escopo analisar as mudanças trazidas historicamente e que levaram a construção de um modelo pós-positivista, suas consequentes influências no Direito Constitucional e na ciência do Direito como um todo.

\footnotetext{
${ }^{3}$ BAUMAN, Zygmunt. Modernidade líquida. Trad. de: Plínio Dentizien, Rio de Janeiro: Jorge Zahar, 2001.

${ }^{4}$ BARROSO, Luiz Roberto. 0 direito constitucional e a efetividade de suas normas - limites e possibilidades da Constituição brasileira. - 7a.ed. - Rio de Janeiro: Renovar, 2003.

${ }^{5}$ HESSE, Konrad. A força normativa da Constituição. Porto Alegre: Sérgio Antonio Fabris, 1991.
} 
PIASSA, Felipe José e DIAS, Bruno Smolarek. Influências pós-positivistas ao novo direito constitucional e o fenômeno da constitucionalização do direito. Revista Eletrônica Direito e Política, Programa de Pós-Graduação Stricto Sensu em Ciência Jurídica da UNIVALI, Itajaí, v.10, n.3, $2^{\circ}$ quadrimestre de 2015. Disponível em: www.univali.br/direitoepolitica - ISSN 1980-7791.

\section{A CIÊNCIA JURÍDICA E AS SUAS ERAS}

A Ciência Jurídica historicamente pode ser dividida em dois grandes marcos ou paradigmas, que predominantemente embasaram a construção do direito posto: o jusnaturalismo e o positivismo jurídico.

Neste momento do trabalho, convém analisar brevemente as características gerais de cada uma destas correntes, a fim de que se possa apresentar a nova base teórica que é crescente na teoria geral do Direito, assim como as mudanças trazidas à matéria pertinente ao Direito Constitucional, o qual é objetivo-fim deste singelo trabalho.

\subsection{Jusnaturalismo e Positivismo Jurídico}

O jusnaturalismo, corrente que por mais tempo ensejou o que figuraria como direito posto, figurando desde a primeira ordem legal estabelecida, passando até a positivação do direito no século XIX - sem olvidar, ainda, daqueles que persistem na aceitação de seus postulados ${ }^{6}$-, segundo Maria Helena Diniz, conceituando o jusnaturalismo dos escolásticos, trata-se:

Como um conjunto de normas ou de princípios morais, que são imutáveis, consagrados ou não na legislação da sociedade, visto que resultam da natureza das coisas e do homem, sendo por isso apreendidos imediatamente pela inteligência humana como verdadeiros ${ }^{7}$.

Luís Roberto Barroso, em seu artigo "Neoconstitucionalismo e Constitucionalização do Direito" (2005), verbalizou acerca desta corrente de pensamento:

\footnotetext{
${ }^{6}$ ZANON JUNIOR. Orlando Luiz. Teoria Complexa do Direito. 2013. 439. Tese (Doutorado em Ciência Jurídica). Universidade do Vale do Itajaí - UNIVALI. Itajaí, SC, 2013.

7 DINIZ, Maria Helena. Compêndio de Introdução à Ciência do Direito: introdução à teoria geral do direito, à filosofia do direito, à sociologia jurídica e à lógica jurídica. Norma jurídica e aplicação do Direito. 21. Ed. Rev. E atual. São Paulo: Saraiva. 2010. P. 38.
} 
PIASSA, Felipe José e DIAS, Bruno Smolarek. Influências pós-positivistas ao novo direito constitucional e o fenômeno da constitucionalização do direito. Revista Eletrônica Direito e Política, Programa de Pós-Graduação Stricto Sensu em Ciência Jurídica da UNIVALI, Itajaí, v.10, n.3, $2^{\circ}$ quadrimestre de 2015. Disponível em: www.univali.br/direitoepolitica - ISSN 1980-7791.

O jusnaturalismo moderno, desenvolvido a partir do século XVI, aproximou a lei da razão e transformou-se na filosofia natural do Direito. Fundado na crença em princípios de justiça universalmente válidos, foi o combustível das revoluções liberais e chegou ao apogeu com as Constituições escritas e as codificações. Considerado metafísico e anticientífico, o direito natural foi empurrado para a margem da história pela ascensão do positivismo jurídico, no final do século XIX .

Zanon Junior, ao ponderar sobre a característica mais marcante de tal paradigma, narrou consistir (2013):

Em afirmar a existência de uma ordem jurídica universalmente válida, historicamente invariável e axiologicamente superior àquela produzida pelo Estado, a qual decorreria da própria natureza humana e seria aferível somente pela boa razão.

Portanto, nesse norte, podemos concluir o jusnaturalismo como princípios morais superiores hierarquicamente, independentes e permanentes à ordem positivada por um determinado Estado, cultura ou civilização, sendo que este vincula o próprio ser humano para com seu próximo, seja de forma individual ou coletiva.

Continua Zanon Junior ${ }^{9}$, estabelecendo duas ordens normativas distintas, sendo a primeira o direito natural, de forma universal, invariável e superior, da qual decorrem as prerrogativas que fundamentariam a sua ordem, a qual se apresenta como viés positivista. Nesse sentido, caberia apenas ao aplicador do Direito reconhecer a superioridade do direito natural, e aplicá-la em detrimento daquela positivada pelos governantes.

\footnotetext{
${ }^{8}$ BARROSO, Luiz Roberto. Neoconstitucionalismo e constitucionalização do Direito. 0 triunfo tardio do Direito Constitucional no Brasil. Jus Navigandi. Teresina. Ano 10, n. 851, v. 1. Nov. 2005. Disponível em: <http://jus.com.br/artigos/7547>. Acesso em: 1 abr. 2014.

9 ZANON JUNIOR. Orlando Luiz. Teoria Complexa do Direito. 2013. 439. Tese (Doutorado em Ciência Jurídica). Universidade do Vale do Itajaí - UNIVALI. Itajaí, SC, 2013.
} 
PIASSA, Felipe José e DIAS, Bruno Smolarek. Influências pós-positivistas ao novo direito constitucional e o fenômeno da constitucionalização do direito. Revista Eletrônica Direito e Política, Programa de Pós-Graduação Stricto Sensu em Ciência Jurídica da UNIVALI, Itajaí, v.10, n.3, $2^{\circ}$ quadrimestre de 2015. Disponível em: www.univali.br/direitoepolitica - ISSN 1980-7791.

Contudo, a dificuldade de se estabelecer quais são os ditos direitos superiores, com base apenas no argumento da racionalidade - o que tornaria tais decisões imprecisas e ambíguas -, começou lentamente a ferir este paradigma ${ }^{10}$.

As chagas abertas não cicatrizaram, muito pelo contrário. Com a instituição do Estado moderno, que tomou exclusivamente para si a competência legiferante, assim como o fortalecimento do movimento da codificação - cujo termo inaugural foi o Código Civil Napoleônico -, trespassou a lança dos enunciados escritos ao coração dos postulados jusnaturalistas, fulminado no fim daquela era da ciência jurídica.

O positivismo jurídico, corrente antagônica àquela dantes exposta, caracteriza-se pela rejeição à forma abstrata do direito natural, por julgá-la metafísica e científica, sistematizando o Direito à frieza e exatidão da ciência.

De acordo com esta vertente da ciência jurídica, não devem ser considerados na busca da justiça os juízos de valor, devendo o intérprete do direito estudar as normas que compõe a ordem jurídica vigente, os quais são observáveis e concretos.

Nesse sentido, pondera Maria Helena Diniz:

O positivismo, ao arredar o direito natural, procurar reconhecer tão somente o direito positivo, no sentido de direito vigente e eficaz em determinada sociedade, limitando assim o conhecimento científico-jurídico ao estudo das legislações positivas, consideradas como fenômenos espaciotemporais ${ }^{11}$.

\footnotetext{
${ }^{10}$ ZANON JUNIOR. Orlando Luiz. Teoria Complexa do Direito. 2013. 439. Tese (Doutorado em Ciência Jurídica). Universidade do Vale do Itajaí - UNIVALI. Itajaí, SC, 2013.

${ }^{11}$ DINIZ, Maria Helena. Compêndio de Introdução à Ciência do Direito: introdução à teoria geral do direito, à filosofia do direito, à sociologia jurídica e à lógica jurídica. Norma jurídica e aplicação do Direito. 21. Ed. Rev. E atual. São Paulo: Saraiva. 2010. P. 38.
} 
PIASSA, Felipe José e DIAS, Bruno Smolarek. Influências pós-positivistas ao novo direito constitucional e o fenômeno da constitucionalização do direito. Revista Eletrônica Direito e Política, Programa de Pós-Graduação Stricto Sensu em Ciência Jurídica da UNIVALI, Itajaí, v.10, n.3, $2^{\circ}$ quadrimestre de 2015. Disponível em: www.univali.br/direitoepolitica - ISSN 1980-7791.

O positivismo jurídico também se contrapõe ao direito natural na medida em que esta emana da própria natureza do homem, de sua cultura ou de sua religião, e aquela origina-se sempre do Estado.

O juspositivismo teve seu ápice nas lições do austríaco Hans Kelsen, um de seus principais defensores e desenvolvedores. Autor da famigerada Teoria Pura do Direito (em alemão Reine Rechtslehr), Kelsen desenvolveu uma teoria literalmente pura para a ciência do direito, a qual não poderia sofrer qualquer influência externa, seja ela moral, política, religiosa ou ideológica. Pretendia levar a lógica e exatidão das outras ciências para o direito ${ }^{12}$.

Ao revés da concepção atual da ciência jurídica - fenômeno mutável que objetiva solucionar todos os conflitos sociais, sejam aqueles instalados ou que se instalarão, os quais notoriamente mostram-se impossíveis de serem previstos pelo legislador - Kelsen defendia a existência do direito como ciência pura erigida sobre os métodos científicos positivistas adaptados a ela.

Nas palavras do próprio Kelsen:

Quando a si própria se designa como "pura" teoria do Direito, isto significa que ela se propõe a garantir um conhecimento apenas dirigido ao Direito e excluir desse conhecimento tudo quanto não pertença ao seu objeto, tudo quanto não possa, rigorosamente, determinar como Direito. Quer isto dizer que ela pretende libertar a ciência jurídica de todos os elementos que the são estranhos. Esse é o seu princípio metodológico fundamental ${ }^{13}$

\footnotetext{
${ }^{12}$ KELSEN, Hans. Teoria pura do direito. Trad. de João Batista Machado. São Paulo: Martins Fontes, 1997.

${ }^{13}$ Idem. P. 01.
} 
PIASSA, Felipe José e DIAS, Bruno Smolarek. Influências pós-positivistas ao novo direito constitucional e o fenômeno da constitucionalização do direito. Revista Eletrônica Direito e Política, Programa de Pós-Graduação Stricto Sensu em Ciência Jurídica da UNIVALI, Itajaí, v.10, n.3, $2^{\circ}$ quadrimestre de 2015. Disponível em: www.univali.br/direitoepolitica - ISSN 1980-7791.

Ainda de acordo com Kelsen, a justiça não poderia nem mesmo ser usada como parâmetro de julgamento, haja vista a relatividade e subjetividade do conceito de justo e injusto ${ }^{14}$.

Por seu turno, o italiano Norberto Bobbio, estudioso da filosofia do direito e do positivismo jurídico, o Direito deveria fundar-se tão somente em juízos de fato, afastando qualquer juízo de valor. Confira-se:

A ciência exclui do próprio âmbito os juízos de valor, porque ela deseja ser um conhecimento puramente objetivo da realidade, enquanto os juízos em questão são sempre subjetivos (ou pessoais) e consequentemente contrários à exigência da objetividade ${ }^{15}$.

Parafraseando Luís Roberto Barroso, podemos dizer que a lei por um bom tempo foi vista como expressão superior da razão ${ }^{16}$.

Ao juiz incumbia no positivismo jurídico, a atividade de somente revelar e aplicar aquilo que já estava positivado na lei, sendo, nas palavras de Montesquieu: "apenas a boca que pronuncia as palavras da lei; seres inanimados que não lhe podem moderar nem a força, nem o rigor"17.

Zanon Júnior, sobre o tema, definiu como seus aspectos mais marcantes:

A separação entre Direito e Moral, a formação do Ordenamento Jurídico exclusivamente (ou, ao menos, prevalecentemente) por Regras positivadas, a construção do

\footnotetext{
14 KELSEN, Hans. Teoria geral do direito e do Estado. 4 ed. Tradução de: Luís Carlos Borges. São Paulo: Martins Fontes, 2005. P. 11.

15 BOBBIO, Norberto. 0 positivismo jurídico: lições de filosofia do direito. Trad. Mario Pugliesi. São Paulo: Icone, 1995.

16 BARROSO, Luiz Roberto. Curso de Direito Constitucional Contemporâneo: Os conceitos fundamentais e a construção do novo modelo. 2. Ed. São Paulo: Saraiva, 2010. P. 239.

17 MONTESQUIEU, Charles de Secondat. O espírito das leis: as formas de governo, a divisão dos poderes. Trad. de: Pedro Vieira Mota. São Paulo: Saraiva, 1987. P. 176.
} 
PIASSA, Felipe José e DIAS, Bruno Smolarek. Influências pós-positivistas ao novo direito constitucional e o fenômeno da constitucionalização do direito. Revista Eletrônica Direito e Política, Programa de Pós-Graduação Stricto Sensu em Ciência Jurídica da UNIVALI, Itajaí, v.10, n.3, $2^{\circ}$ quadrimestre de 2015. Disponível em: www.univali.br/direitoepolitica - ISSN 1980-7791.

sistema escalonado só pelo critério de validade formal, a aplicação do Direito posto mediante subsunção e a discricionariedade judicial para resolução dos chamados casos difíceis (hard cases). Tais peculiaridades foram cunhadas pelos cientistas do Direito justamente para assegurar uma vinculação dedutiva subsunção da autoridade à lei (Direito posto), num esforço para afastar as incertezas e inseguranças decorrentes do uso ilimitado de uma suposta razão superior, lastrada em alegados valores morais absolutos e inquestionáveis, ficticiamente válidos e eficazes em todo tempo e lugar ${ }^{18}$.

Contudo, a ciência jurídica nos moldes idealizados de acordo com o positivismo jurídico, no decorrer de sua vigência mostrou-se ineficaz e falha, totalmente a descontento de como fora cunhada.

O enfraquecimento deste paradigma apenas aumentara, até que sobreveio a queda do regime fascista e nazista, na Itália e Alemanha, respectivamente, com o fim da Segunda Guerra Mundial, sendo sua derrocada a tais acontecimentos associada. Tais movimentos promoveram a barbárie sob o estrito cumprimento da lei. Os principais acusados de Nuremberg escudaram sua defesa sob o argumento da obediência das ordens emanadas da autoridade competente ${ }^{19}$.

A indiferença à moral e à ética passou a não ter mais lugar no Direito. Concluiuse que o texto frio de uma determinada lei positivada e de conteúdo genérico e limitado não poderia figurar como direito posto, de modo a aplicar aprioristicamente a justiça. Continua Luís Roberto Barroso:

O positivismo pretendeu ser uma teoria do Direito, na qual o estudioso assumisse uma atitude cognoscitiva (de conhecimento), fundada em juízos de fato. Mas resultou sendo uma ideologia, movida por juízos de valor, por ter se tornado não apenas um modo de entender o Direito, como

\footnotetext{
${ }^{18}$ ZANON JUNIOR, Orlando Luiz. Teoria complexa do Direito. 2013. 439. Tese (Doutorado em Ciência Jurídica). Universidade do Vale do Itajaí - UNIVALI. Itajaí, 2013. P. 40.

${ }^{19}$ BARROSO, Luiz Roberto. O direito constitucional e a efetividade de suas normas: limites e possibilidades da Constituição brasileira. 7. Ed. Rio de Janeiro: Renovar, 2003. P. 290.
} 
PIASSA, Felipe José e DIAS, Bruno Smolarek. Influências pós-positivistas ao novo direito constitucional e o fenômeno da constitucionalização do direito. Revista Eletrônica Direito e Política, Programa de Pós-Graduação Stricto Sensu em Ciência Jurídica da UNIVALI, Itajaí, v.10, n.3, $2^{\circ}$ quadrimestre de 2015. Disponível em: www.univali.br/direitoepolitica - ISSN 1980-7791.

também de querer o Direito. $O$ fetiche da lei e o legalismo acrítico, subprodutos do positivismo jurídico, serviram de disfarce para autoritarismos de matizes variados. A idéia de que o debate acerca da justiça se encerrava quando da positivação da norma tinha um caráter legitimador da ordem estabelecida. Qualquer ordem ${ }^{20}$.

Feitas estas breves considerações acerca dos jusnaturalismo e sobre o positivismo jurídico, passarei a tecer no tópico seguinte a respeito do póspositivismo jurídico, a nova vertente da ciência jurídica.

\subsection{O pós-positivismo}

Com a ineficácia e consequente decadência do positivismo jurídico nos termos já alinhavados, em que o Direito era sinônimo da lei e que a ética e a moral não faziam parte deste dueto, e que resultara no preço altíssimo ainda não quitado pela humanidade, fez-se imperioso o surgimento de um novo postulado.

Contudo, os tempos já eram outros. Nessa toada, Luís Roberto Barroso:

O discurso científico impregnara o Direito. Seus operadores não desejavam o retorno puro e simples do jusnaturalismo, aos fundamentos vagos, abstratos ou metafísicos de uma razão subjetiva ${ }^{21}$.

Nesse interregno, apto à fazer as vezes do "meio termo": sem retroagir a metafísica do jusnaturalismo ou reprimir e restringir o Direito à norma positivada, surge o pós-positivismo. É o que leciona Luís Roberto Barroso:

O pós-positivismo não surge com o ímpeto de descontrução, mas com uma desconstrução do conhecimento convencional. Ele inicia sua trajetória guardando deferência relativa ao

\footnotetext{
${ }^{20}$ BARROSO, Luiz Roberto. Curso de Direito Constitucional Contemporâneo: Os conceitos fundamentais e a construção do novo modelo. 2. Ed. São Paulo: Saraiva, 2010. P. 239.

${ }^{21}$ BARROSO, Luiz Roberto. Fundamentos teóricos e filosóficos do novo Direito Constitucional Brasileiro. Revista de Direito Administrativo. Rio de Janeiro. V. 225. P. 5-37, Jul. -Set. , 2001.
} 
PIASSA, Felipe José e DIAS, Bruno Smolarek. Influências pós-positivistas ao novo direito constitucional e o fenômeno da constitucionalização do direito. Revista Eletrônica Direito e Política, Programa de Pós-Graduação Stricto Sensu em Ciência Jurídica da UNIVALI, Itajaí, v.10, n.3, $2^{\circ}$ quadrimestre de 2015. Disponível em: www.univali.br/direitoepolitica - ISSN 1980-7791.

ordenamento positivo, mas nele reintroduzindo as ideias de justiça e legitimidade ${ }^{22}$.

Esse festejado fenômeno: o retorno dos valores, a reaproximação entre ética e Direito, foi denominado por alguns autores alemães como "virada kantiana".

Tais valores, igualmente compartilhados pela sociedade em dado momento e lugar, solidificados no direito natural, a partir de então se incorporariam ao Direito, tornando-se parte intrínseca deste, de modo que passariam a ser materializados em princípios e encontrar alento na Constituição, seja explícita ou implicitamente.

Ressalta Luís Roberto Barroso, que a novidade não está na existência e reconhecimento dos princípios pela ordem jurídica, ao passo que estes há tempos fazem da parte do Direito, direta ou indiretamente, o que há incorporase ao novo modelo é o reconhecimento de sua normatividade. Vejamos o que ensina o atual ministro do Pretório Excelso:

Os princípios constitucionais, portanto, explícitos ou não, passam a ser a síntese dos valores abrigados no ordenamento jurídico. Eles espelham a ideologia da sociedade, seus postulados básicos, seus fins. Os princípios dão unidade e harmonia ao sistema, integrando suas diferentes partes e atenuando tensões normativas. De parte isto, servem de guia para o intérprete, cuja atuação deve pautar-se pela identificação do princípio maior que rege o tema apreciado, descendo do mais genérico ao mais específico, até chegar a regra concreta que vai reger a espécie. Estes os papéis desempenhados pelos princípios: a) condensar valores; b) dar unidade ao sistema; c) condicionar a atividade do intérprete ${ }^{23}$.

\footnotetext{
22 BARROSO, Luiz Roberto. Fundamentos teóricos e filosóficos do novo Direito Constitucional Brasileiro. Revista de Direito Administrativo. Rio de Janeiro. V. 225. P. 5-37, Jul. -Set. , 2001. P. 30.

${ }^{23}$ Idem. P. 31.
} 
PIASSA, Felipe José e DIAS, Bruno Smolarek. Influências pós-positivistas ao novo direito constitucional e o fenômeno da constitucionalização do direito. Revista Eletrônica Direito e Política, Programa de Pós-Graduação Stricto Sensu em Ciência Jurídica da UNIVALI, Itajaí, v.10, n.3, $2^{\circ}$ quadrimestre de 2015. Disponível em: www.univali.br/direitoepolitica - ISSN 1980-7791.

Os princípios, portanto, passaram a ter força normativa e abandonaram o status de dimensão puramente axiológica, sem eficácia jurídica ou aplicabilidade direta ou imediata.

Hodiernamente, a dogmática traz às normas em geral e, especificamente à norma constitucional, a sua divisão em duas categorias: regras e princípios.

Robert Alexy diferencia estas duas categorias:

Regras são normas que ordenam, proíbem ou permitem algo definitivamente, ou autorizam a algo definitivamente. Eles contêm um dever definitivo. Quando os seus pressupostos estão cumpridos, produz-se a consequência jurídica. Se não se quer aceitar esta, deve ou declarar-se a regra como inválida e, com isso, despedi-la do ordenamento jurídico, ou, então, inserir-se uma exceção na regra e, nesse sentido, criar uma nova regra. A forma de aplicação das regras é a subsunção. Princípios contêm, pelo contrário, um dever ideal. Eles são mandamentos a serem otimizados. Como tais, eles não contêm um dever definitivo, mas somente um dever prima-facie. Eles exigem que algo seja realizado em medida tão alta quanto possível relativamente às possibilidades fáticas e jurídicas. [...] Como mandamentos ideais, princípios exigem mais do que é possível realmente. Eles colidem com outros princípios. A forma de aplicação para eles típica é, por isso, a ponderação. Somente a ponderação leva do dever prima-facie ideal ao dever real e definitivo ${ }^{24}$.

Entendem-se como regras, portanto, normas de conteúdo fechado, imediato, objetivo e de aplicação apriorísitica. São normas aplicadas sobre a proposição do "tudo ou nada" (all or nothing), ou seja, tão logo ocorra os fatos nela previstos, tem-se sua aplicação direta, independentemente de juízo de valor

Para melhor ilustrar a aplicabilidade da norma, podemos usar do exemplo banal do jogador de futebol que será expulsando na hipótese de ser sancionado com

\footnotetext{
${ }^{24}$ ALEXY, Robert. Constitucionalismo discursivo. Trad. De Luís Afonso Heck. Porto Alegre: Livraria do Advogado, 2007.
} 
PIASSA, Felipe José e DIAS, Bruno Smolarek. Influências pós-positivistas ao novo direito constitucional e o fenômeno da constitucionalização do direito. Revista Eletrônica Direito e Política, Programa de Pós-Graduação Stricto Sensu em Ciência Jurídica da UNIVALI, Itajaí, v.10, n.3, $2^{\circ}$ quadrimestre de 2015. Disponível em: www.univali.br/direitoepolitica - ISSN 1980-7791.

dois cartões amarelos na mesma partida. Ora, ou o árbitro de futebol considera a regra válida e a aplica expulsando o jogador, ou, ao revés, a considera inválida e afasta a sua aplicação.

Portanto, a regra somente deixará de incidir sobre um determinado fato se for inválida, se houver outra mais específica ou se não estiver em vigor. A aplicação desta regra ocorre, predominantemente, mediante o convencional critério de subsunção ${ }^{25}$.

Antagonicamente, os princípios, caracterizam-se pelo conteúdo aberto e sua aplicação mediata e casuística. Apresentam-se com certo teor de abstração.

Considerando que detém uma maior carga valorativa, consistente em uma decisão política relevante ou um fundamento ético, os princípios apenas tem o condão de atuar com ares de preâmbulo, ou seja, figurando como um norte a ser seguido ${ }^{26}$.

Em que pese os princípios serem variados, não raras as vezes estes acabam por colidir, pelo qual explica Barroso ${ }^{27}$, se tratar não só de hipótese possível, mas também provável, ante a lógica do sistema dialético.

Diante deste cenário, notadamente os princípios não são aplicados mediante a regra do "tudo ou nada".

A solução para o conflito entre norma-regra $x$ norma-princípio, deve ser solucionado mediante ponderação, técnica desenvolvida pelo autor alemão

\footnotetext{
${ }^{25}$ BARROSO, Luiz Roberto. Fundamentos teóricos e filosóficos do novo Direito Constitucional Brasileiro. Revista de Direito Administrativo. Rio de Janeiro. V. 225. P. 5-37, Jul. -Set. , 2001.

${ }^{26}$ Idem.

${ }^{27}$ Ibidem.
} 
PIASSA, Felipe José e DIAS, Bruno Smolarek. Influências pós-positivistas ao novo direito constitucional e o fenômeno da constitucionalização do direito. Revista Eletrônica Direito e Política, Programa de Pós-Graduação Stricto Sensu em Ciência Jurídica da UNIVALI, Itajaí, v.10, n.3, $2^{\circ}$ quadrimestre de 2015. Disponível em: www.univali.br/direitoepolitica - ISSN 1980-7791.

Robert Alexy ${ }^{28}$, retomando as premissas dantes estabelecidas por Ronald Dworkin.

Tal técnica, que reconhece a importância do princípio, consiste em impor ao intérprete o dever de, por meio de escolhas fundamentadas, escolher a melhor solução a um caso concreto (aplicação casuística), mediante a verificação do peso específico de cada princípio que está sendo contraposto.

Imperioso mencionar, que não há, de forma alguma, o reconhecimento de superioridade de um princípio a outro, mas tão somente a verificação de qual princípio é mais adequado a situação apreciada, com todas as suas particularidades. Rememore-se uma vez mais, que princípios são normas de conteúdo aberto e aplicação mediata e casuística.

Outrossim, cumpre salientar, que não há qualquer hierarquia entre norma-regra e norma-princípio.

Muito embora, de acordo com Luís Roberto Barroso, em algumas situações, um princípio poderá afastar a aplicação de uma regra, enquanto é possível que uma regra excepcione a aplicação de um princípio $^{29}$.

\section{UM NOVO PANORAMA PARA O DIREITO CONSTITUCIONAL}

\subsection{Uma nova hermenêutica constitucional}

Nos termos suso esposados, conclui-se que a era do pós-positivismo e sua consequente normatividade dos princípios influenciaram na formação de uma nova hermenêutica constitucional e no movimento que ficou conhecido como

\footnotetext{
${ }^{28}$ ALEXY, Robert. Teoria dos direitos fundamentais. Trad. De Virgílio Afonso da Silva. São Paulo: Malheiros, 2008.

29 BARROSO, Luiz Roberto. Fundamentos teóricos e filosóficos do novo Direito Constitucional Brasileiro. Revista de Direito Administrativo. Rio de Janeiro. V. 225. P. 5-37, Jul. -Set. , 2001.
} 
PIASSA, Felipe José e DIAS, Bruno Smolarek. Influências pós-positivistas ao novo direito constitucional e o fenômeno da constitucionalização do direito. Revista Eletrônica Direito e Política, Programa de Pós-Graduação Stricto Sensu em Ciência Jurídica da UNIVALI, Itajaí, v.10, n.3, $2^{\circ}$ quadrimestre de 2015. Disponível em: www.univali.br/direitoepolitica - ISSN 1980-7791.

constitucionalização do direito, este último, fenômeno que melhor será desenvolvido no tópico seguinte.

Uma das principais mudanças trazidas pelas transformações mencionadas foi o reconhecimento de força normativa à norma constitucional.

Deixou-se e superou-se o antigo modelo de constituição em que o texto constitucional trazia apenas caráter político. Neste modelo, o conteúdo trazido pela Constituição era sempre condicionado à liberdade de conformação do legislador ou à discricionariedade do administrador, não restando ao Judiciário nenhuma função relevante na realização de seu conteúdo.

Nesse sentido, é o que ensina Luís Roberto Barroso:

Antes de 1945, vigorava na maior parte da Europa um modelo de supremacia do Poder Legislativo, na linha da doutrina inglesa de soberania do Parlamento e da concepção francesa da lei como expressão da vontade geral. A partir do final da década de 40, todavia, a onda constitucional trouxe não apenas novas constituições, mas também um novo modelo, inspirado pela experiência americana: o da supremacia da Constituição. A fórmula envolvia a constitucionalização dos direitos fundamentais, que ficavam imunizados em relação ao processo político majoritário: sua proteção passava a caber ao Judiciário. Inúmeros países europeus vieram a adotar um modelo próprio de controle de constitucionalidade, associado à criação de tribunais constitucionais ${ }^{30}$.

Hodiernamente, a Constituição apresenta-se no centro do ordenamento jurídico, impondo-se com o status de astro-rei aos demais sistemas ou "planetas" - como os ramos direito civil, penal, eleitoral, ambiental, processual cível e penal, dentre outros - que são irradiados por seus efeitos, consistindo, assim, em uma espécie de sistema orbital.

\footnotetext{
${ }^{30}$ BARROSO, Luiz Roberto. Neoconstitucionalismo e constitucionalização do Direito. 0 triunfo tardio do Direito Constitucional no Brasil. Jus Navigandi, Teresina, ano 10, n. 851, 1 nov. 2005. Disponível em: <http://jus.com.br/artigos/7547>. Acesso em: 1 abr. 2014.
} 
PIASSA, Felipe José e DIAS, Bruno Smolarek. Influências pós-positivistas ao novo direito constitucional e o fenômeno da constitucionalização do direito. Revista Eletrônica Direito e Política, Programa de Pós-Graduação Stricto Sensu em Ciência Jurídica da UNIVALI, Itajaí, v.10, n.3, $2^{\circ}$ quadrimestre de 2015. Disponível em: www.univali.br/direitoepolitica - ISSN 1980-7791.

A Constituição passa a impor uma supremacia material e axiológica, tornando-se um verdadeiro filtro pelo qual procede-se a interpretação da norma infraconstitucional.

Sempre que houver a aplicação de uma norma ordinária, impreterivelmente realizar-se-á pelo aplicador do direito uma espécie de controle de constitucionalidade e verificar-se-á o sentido e o alcance que uma determinada norma infraconstitucional terá sob o prisma dos valores constitucionais. É possível concluir, assim, que toda interpretação jurídica acaba se tornando uma interpretação constitucional.

É o que preceitua Luís Roberto Barroso:

A Constituição passa a ser, assim, não apenas um sistema em si - com a sua ordem, unidade e harmonia - mas também um modo de olhar e interpretar todos os demais ramos do Direito. Esse fenômeno, identificado por alguns autores como filtragem constitucional, consiste em que toda a ordem jurídica deve ser lida e apreendida sob a lente da Constituição, de modo a realizar os valores nela consagrados. A constitucionalização do direito infraconstitucional não identifica apenas a inclusão na Lei Maior de normas próprias de outros domínios, mas, sobretudo, a reinterpretação de seus institutos sob uma ótica constitucional ${ }^{31}$.

Desse modo, surgindo uma norma infraconstitucional ou mesmo um dispositivo que venha a infringir um determinado axioma previsto na Lei Maior, este estará fadado à ineficácia.

No Brasil, por força do artigo 102 da Constituição Federal, o Supremo Tribunal Federal é o guardião da Lei Fundamental, cabendo-Ihe a função exclusiva de realizar o controle de constitucionalidade na modalidade concentrado, seja de forma preventiva (antes da elaboração da lei, impedindo que um projeto de lei inconstitucional venha a ser promulgado) ou repressiva (realizado após a

${ }^{31}$ BARROSO, Luiz Roberto. Fundamentos teóricos e filosóficos do novo Direito Constitucional Brasileiro. Revista de Direito Administrativo. Rio de Janeiro. V. 225. P. 5-37, Jul. -Set. , 2001. P. 31 . 
PIASSA, Felipe José e DIAS, Bruno Smolarek. Influências pós-positivistas ao novo direito constitucional e o fenômeno da constitucionalização do direito. Revista Eletrônica Direito e Política, Programa de Pós-Graduação Stricto Sensu em Ciência Jurídica da UNIVALI, Itajaí, v.10, n.3, $2^{\circ}$ quadrimestre de 2015. Disponível em: www.univali.br/direitoepolitica - ISSN 1980-7791.

promulgação do diploma, com o fim de retirar uma lei ou ato normativo da esfera jurídica).

Outrossim, outra relevante transformação que passou a ciência jurídica tratando-se esta de uma consequência da força normativa da Constituição - deuse por meio do desenvolvimento de uma nova interpretação constitucional, tendo em vista que os métodos tradicionais mostraram-se insuficientes à elucidação dos conflitos cotidianamente renovados. Justificou-se, então, a necessidade de instrumentos como as de cláusulas gerais, a ponderação, a argumentação jurídica, dentre outros.

Complementa Luís Roberto Barroso:

Sem prejuízo do que se vem de afirmar, o fato é que as
especificidades das normas constitucionais (v. supra)
levaram a doutrina e a jurisprudência, já de muitos anos, a
desenvolver ou sistematizar um elenco próprio de princípios
aplicáveis à interpretação constitucional. Tais princípios, de
natureza instrumental, e não material, são pressupostos
lógicos, metodológicos ou finalísticos da aplicação das
normas constitucionais. São eles, na ordenação que se
afigura mais adequada para as circunstâncias brasileiras: o
da supremacia da Constituição, o da presunção de
constitucionalidade das normas e atos do Poder Público, o da
interpretação conforme a Constituição, o da unidade, o da
razoabilidade e o da efetividade ${ }^{32}$.

Contudo, imperioso mencionar, que os critérios tradicionais de solução de eventuais conflitos normativos não deixaram de ser usados ou perderam sua eficácia - muito pelo contrário, estes resolvem boa parte das questões jurídicas. São eles: (a) o hierárquico, pelo qual a lei superior prevalecerá sobre a inferior; (b) o temporal, quando deixará de se aplicar a lei anterior em virtude da

\footnotetext{
32 BARROSO, Luiz Roberto. Neoconstitucionalismo e constitucionalização do Direito. 0 triunfo tardio do Direito Constitucional no Brasil. Jus Navigandi, Teresina, ano 10, n. 851, 1 nov. 2005. Disponível em: <http://jus.com.br/artigos/7547>. Acesso em: 1 abr. 2014.
} 
PIASSA, Felipe José e DIAS, Bruno Smolarek. Influências pós-positivistas ao novo direito constitucional e o fenômeno da constitucionalização do direito. Revista Eletrônica Direito e Política, Programa de Pós-Graduação Stricto Sensu em Ciência Jurídica da UNIVALI, Itajaí, v.10, n.3, $2^{\circ}$ quadrimestre de 2015. Disponível em: www.univali.br/direitoepolitica - ISSN 1980-7791.

existência de uma lei posterior que discipline a matéria; (c) e o especial, em que a legislação especial irá prevalecer frente a um diploma genérico ${ }^{33}$.

Ocorre que a comunidade jurídica se deu conta de:

[...] uma situação de carência: as categorias tradicionais da interpretação jurídica não são inteiramente ajustadas para a solução de um conjunto de problemas ligados à realização da vontade constitucional. A partir daí deflagrou-se 0 processo de elaboração doutrinária de novos conceitos e categorias, agrupados sob a denominação de nova interpretação constitucional, que se utiliza de um arsenal teórico diversificado, em um verdadeiro sincretismo metodológico ${ }^{34}$.

A interpretação jurídica tradicional, que desenvolvia-se sob o papel da norma - a qual trazia em seu relato a solução para os problemas jurídicos - e do juiz, em que incumbia o dever de localizar no ordenamento jurídico a norma que previa a solução adequada a um determinado caso a ser resolvido, aplicando-lhe tal solução apresentada, passam a ser insuficientes à efetiva resolução de conflitos.

Diante deste cenário, em que o direito constitucional urgia por mudanças que atualizassem a interpretação jurídica, com o escopo de acompanhar a mutação que é constante em tempos de modernidade líquida, verificou-se que a norma nem sempre traz a solução para os problemas jurídicos em seu relato, eis que esta também não se atualiza com a mesma velocidade em que os fenômenos sociais ocorrem/desenvolvem-se/modificam-se.

No que tange ao papel do juiz, já não lhe cabia apenas uma função de conhecimento técnico, suficiente a revelar a solução contida no enunciado normativo, mas sim, torna-se verdadeiro intérprete e também participante do

\footnotetext{
${ }^{33}$ Idem.

${ }^{34}$ BARROSO, Luiz Roberto. Neoconstitucionalismo e constitucionalização do Direito. 0 triunfo tardio do Direito Constitucional no Brasil. Jus Navigandi, Teresina, ano 10, n. 851, 1 nov. 2005. Disponível em: <http://jus.com.br/artigos/7547>. Acesso em: 1 abr. 2014.
} 
PIASSA, Felipe José e DIAS, Bruno Smolarek. Influências pós-positivistas ao novo direito constitucional e o fenômeno da constitucionalização do direito. Revista Eletrônica Direito e Política, Programa de Pós-Graduação Stricto Sensu em Ciência Jurídica da UNIVALI, Itajaí, v.10, n.3, $2^{\circ}$ quadrimestre de 2015. Disponível em: www.univali.br/direitoepolitica - ISSN 1980-7791.

processo de criação do Direito, em que atua complementando o trabalho do legislador, ao passo que faz valorações de sentidos para as cláusulas abertas, fazendo, ainda, escolhas entre soluções possíveis.

Tais transformações pelo qual passaram a norma e o juiz deram azo ao surgimento de categorias em que se realiza a interpretação. Dentre elas, destacam-se: (a) as cláusulas gerais, que consistem em conceitos jurídicos indeterminados e de conteúdo aberto, que fornecem um início de significação a ser complementado pelo intérprete, levando em conta as circunstâncias do caso concreto; (b) os princípios, como já exposto, são normas que estabelecem determinados valores ou indicam fins públicos, caracterizando-se pelo conteúdo aberto e sua aplicação mediata e casuística; (c) a colisão de normas constitucionais, que ocorre quando duas normas de igual hierarquia colidem em abstrato, e que deverá ser buscada pelo intérprete a solução do problema, mediante a criação do Direito aplicável ao caso concreto; (d) a ponderação, que tem por esteio o princípio da razoabilidade, advém da colisão de normas constitucionais, é a técnica pela qual o intérprete procederá à escolha do direito que deve prevalecer no caso concreto, por melhor realizar a vontade constitucional integralmente interpretada; (e) a argumentação, que corresponde a uma interpretação aplicada aos chamados hard cases, os quais apresentam mais de uma solução possível e razoável ao caso concreto, deverá ser aplicada pelo juiz, buscando sempre aplicar a decisão abstrata tomada pelo legislador ${ }^{35}$.

Desse modo, diante das influências trazidas pelo pós-positivismo que levaram as mudanças no Direito Constitucional neste item expostas, dentre as quais destacam-se a expansão da jurisdição constitucional e o surgimento de uma nova dogmática da interpretação constitucional, desenvolveu-se o fenômeno conhecido como constitucionalização do direito, que será abordado no tópico seguinte.

${ }^{35}$ BARROSO, Luiz Roberto. Neoconstitucionalismo e constitucionalização do Direito. $\mathbf{0}$ triunfo tardio do Direito Constitucional no Brasil. Jus Navigandi, Teresina, ano 10, n. 851, 1 nov. 2005. Disponível em: <http://jus.com.br/artigos/7547>. Acesso em: 1 abr. 2014. 
PIASSA, Felipe José e DIAS, Bruno Smolarek. Influências pós-positivistas ao novo direito constitucional e o fenômeno da constitucionalização do direito. Revista Eletrônica Direito e Política, Programa de Pós-Graduação Stricto Sensu em Ciência Jurídica da UNIVALI, Itajaí, v.10, n.3, $2^{\circ}$ quadrimestre de 2015. Disponível em: www.univali.br/direitoepolitica - ISSN 1980-7791.

\subsection{A constitucionalização do Direito}

A constitucionalização do Direito, na acepção desenvolvida no presente trabalho, corresponde a uma irradiação dos valores abrigados nos princípios e regras da Constituição por todo o ordenamento jurídico ${ }^{36}$.

Nesse norte, Luís Roberto Barroso conceitua a constitucionalização do Direito como:

[...] um efeito expansivo das normas constitucionais, cujo conteúdo material e axiológico se irradia, com força normativa, por todo o sistema jurídico Os valores, os fins públicos e os comportamentos contemplados nos princípios e regras da Constituição passam a condicionar a validade e 0 sentido de todas as normas do direito infraconstitucional. Como intuitivo, a constitucionalização repercute sobre a atuação dos três Poderes, inclusive e notadamente nas suas relações com os particulares. Porém, mais original ainda: repercute, também, nas relações entre particulares ${ }^{37}$.

${ }^{36}$ BARROSO, Luiz Roberto. Neoconstitucionalismo e constitucionalização do Direito. 0 triunfo tardio do Direito Constitucional no Brasil. Jus Navigandi, Teresina, ano 10, n. 851, 1 nov. 2005. Disponível em: <http://jus.com.br/artigos/7547>. Acesso em: 1 abr. 2014.

${ }^{37}$ Idem. 
PIASSA, Felipe José e DIAS, Bruno Smolarek. Influências pós-positivistas ao novo direito constitucional e o fenômeno da constitucionalização do direito. Revista Eletrônica Direito e Política, Programa de Pós-Graduação Stricto Sensu em Ciência Jurídica da UNIVALI, Itajaí, v.10, n.3, $2^{\circ}$ quadrimestre de 2015. Disponível em: www.univali.br/direitoepolitica - ISSN 1980-7791.

Pedro Lenza, por seu turno, ao tratar sobre a superação da dicotomia entre direito público e privado, assevera:

\begin{abstract}
Avançando, por outro lado, modernamente, sobretudo em razão da evidenciação de novos direitos e das transformações do Estado (de autoritário/absolutista para liberal e de liberal para social, podendo-se, inclusive, falar em Estado pós-social de direito), cada vez mais se percebe uma forte influência do direito constitucional sobre o direito privado. (...) especialmente diante do princípio da dignidade da pessoa humana, fundamento da República Federativa do Brasil e princípio-matriz de todos os direitos fundamentais (art. 1.0, III, da CF/88), parece mais adequado, então, falar em um direito civil-constitucional, estudando 0 direito privado à luz das regras constitucionais e podendo, inclusive, em muitos casos, reconhecer a aplicação direta dos direitos fundamentais nas relações privadas ${ }^{38}$.
\end{abstract}

Portanto, a Constituição passa a figurar como verdadeiro status de astro-rei aos demais sistemas ou "planetas" - como os ramos direito civil, penal, eleitoral, ambiental, processual cível e penal, dentre outros - que são irradiados por seus efeitos, consistindo, assim, em uma espécie de sistema orbital.

Imperioso mencionar ainda, que cada sistema também se irradia sobre os demais e, inclusive sobre o constitucional, não podendo, certamente, contrariar este último.

Diante deste cenário, Zanon Júnior destaca a possibilidade de aferir três características principais da Constituição, consistentes:

[...] a um, consubstanciar o centro de forças centrípetas materiais e materiais, porquanto atrai para dentro do sistema apenas os argumentos que lhe sejam compatíveis em sua substância e forma, expurgando os demais para fora (forças centrípeta e centrífuga); a dois, exercer uma irradiação normativa sobre os demais elementos decisórios que integram o sistema, conformando as operações

${ }^{38}$ LENZA, Pedro. Direito constitucional esquematizado. Pedro Lenza. 16. ed. rev., atual. e ampl. São Paulo: Saraiva, 2012. 
PIASSA, Felipe José e DIAS, Bruno Smolarek. Influências pós-positivistas ao novo direito constitucional e o fenômeno da constitucionalização do direito. Revista Eletrônica Direito e Política, Programa de Pós-Graduação Stricto Sensu em Ciência Jurídica da UNIVALI, Itajaí, v.10, n.3, $2^{\circ}$ quadrimestre de 2015. Disponível em: www.univali.br/direitoepolitica - ISSN 1980-7791.

interpretativas e aplicativas em que foram empregados (força irradiativa), e, a três, proteger determinadas opções valorativas, caras à determinada tradição jurídica, contra poderes eventuais, a exemplo de maiorias parlamentares temporárias (força contramajoritária) $)^{39}$.

A partir do fenômeno da constitucionalização do Direito, a Constituição passa a ter aplicabilidade direta a diversas situações, seja declarando inconstitucionais as normas incompatíveis com Lei Fundamental, como também, principalmente, interpretando as normas infraconstitucionais conforme a própria Constituição.

\subsection{O objetivo do novo direito constitucional: a efetividade}

Ainda na linha trilhada das características do novo direito constitucional, nada obstante à normatividade da norma constitucional e suas consequências, surge o fundamento da efetividade do próprio direito constitucional, prescindindo de mecanismos de alteração textual, bastante na sua aplicação efetiva.

No Brasil, ela se desenvolveu com o movimento denominado doutrina brasileira da efetividade.

De acordo com Luís Roberto Barroso ${ }^{40}$, referido movimento objetivou não apenas elaborar as categorias dogmáticas da normatividade constitucional, mas também superar disfunções da formação nacional, consistentes na insinceridade normativa, no uso da Constituição como uma mistificação ideológica e na falta de determinação política em dar-lhe cumprimento.

Nessa linha, o mesmo autor asseverou que a essência da doutrina da efetividade é:

\footnotetext{
${ }^{39}$ ZANON JUNIOR, Orlando Luiz. Teoria complexa do Direito. 2013. 439. Tese (Doutorado em Ciência Jurídica). Universidade do Vale do Itajaí - UNIVALI. Itajaí, 2013. P. 269.

${ }^{40}$ BARROSO, Luís Roberto. A Constituição Brasileira de 1988: uma Introdução. In: MARTINS, Ives Granda da Silva; MENDES, Gilmar Ferreira; NASCIMENTO, Carlos Valder do (Coord.). Tratado de Direito Constitucional, v.1 - $2^{\mathrm{a}}$ ed.- São Paulo: Saraiva, 2012.
} 
PIASSA, Felipe José e DIAS, Bruno Smolarek. Influências pós-positivistas ao novo direito constitucional e o fenômeno da constitucionalização do direito. Revista Eletrônica Direito e Política, Programa de Pós-Graduação Stricto Sensu em Ciência Jurídica da UNIVALI, Itajaí, v.10, n.3, $2^{\circ}$ quadrimestre de 2015. Disponível em: www.univali.br/direitoepolitica - ISSN 1980-7791.

tornar as normas constitucionais aplicáveis direta e imediatamente, na extensão máxima de sua densidade normativa. Como consequência, sempre que violado um mandamento constitucional, a ordem jurídica deve prover mecanismos adequados de tutela - por meio da ação e da jurisdição -, disciplinando os remédios jurídicos próprios e a atuação efetiva de juízes e tribunais ${ }^{41}$.

E com o fito de realizar tais propósitos, o movimento da doutrina da efetividade promoveu três mudanças de paradigma no direito constitucional brasileiro.

Nas palavras de Luís Roberto Barroso:

No plano jurídico, atribuiu normatividade plena à Constituição, que se tornou fonte de direitos e de obrigações, independentemente da intermediação do legislador. Do ponto de vista científico ou dogmático, reconheceu ao direito constitucional um objeto próprio e autônomo, estremando-o do discurso puramente político ou sociológico. E, por fim, sob o aspecto institucional, contribuiu para a ascensão do Poder Judiciário no Brasil, dando-Ihe um papel mais destacado na concretização dos valores e dos direitos constitucionais ${ }^{42}$.

É dizer: a partir do momento que a Constituição cria direitos subjetivos, sejam eles políticos, individuais, sociais ou difusos, eles são, em regra, direta e imediatamente exigíveis, tanto do poder público quanto do próprio particular.

E assim, na hipótese de inobservância de direitos previstos na Lei Maior, legitima-se o Poder Judiciário a exercer função jurisdicional no âmbito constitucional, em defesa da Constituição.

\footnotetext{
${ }^{41}$ Idem. P. 35.

${ }^{42}$ BARROSO, Luís Roberto. A Constituição Brasileira de 1988: uma Introdução. In: MARTINS, Ives Granda da Silva; MENDES, Gilmar Ferreira; NASCIMENTO, Carlos Valder do (Coord.). Tratado de

Direito Constitucional, v.1 - $2^{\mathrm{a}}$ ed.- São Paulo: Saraiva, 2012. P. 35.
} 
PIASSA, Felipe José e DIAS, Bruno Smolarek. Influências pós-positivistas ao novo direito constitucional e o fenômeno da constitucionalização do direito. Revista Eletrônica Direito e Política, Programa de Pós-Graduação Stricto Sensu em Ciência Jurídica da UNIVALI, Itajaí, v.10, n.3, $2^{\circ}$ quadrimestre de 2015. Disponível em: www.univali.br/direitoepolitica - ISSN 1980-7791.

Garante-se, dessa forma, que todas as normas constitucionais apresentem-se eficazes sem a interferência de lesão ou ameaça de lesão a direitos nela previstos $^{43}$.

Portanto, tanto como determinado direito previsto na Constituição deve ser observado com força normativa, igualmente tal direito deve ser aplicado de maneira efetiva. Noutras palavras, direito constitucional é norma e, obrigatoriamente, deve ser cumprido em processos dependentes de alteração textual, bem como exige ser aplicado efetivamente e concretamente.

Dessarte, o neoconstitucionalismo, com vistas a garantir a mencionada normatividade constitucional, traz como uma de suas máximas a busca pela efetividade, almejando não apenas atrelar o constitucionalismo a ideia de limitação do poder público, mas, principalmente, buscar a eficácia da Constituição como concretização dos direitos tutelados, notadamente os direitos fundamentais ${ }^{44}$.

\section{CONSIDERAÇÕES FINAIS}

Mudanças. Na modernidade líquida já referida, talvez seja exagero asseverar que desde a introdução até a conclusão deste trabalho o cenário a que nos referíamos não se apresenta igual ou mesmo se desfez. Talvez não seja.

Ao longo do presente trabalho presenciamos as mudanças de paradigmas enfrentadas pelo Direito, desde os primórdios do direito natural, passando pela sua era exclusivamente científica do positivismo jurídico e sua posterior derrocada, até o surgimento da normatividade dos princípios, principal característica do pós-positivismo.

\footnotetext{
${ }^{43}$ AGRA, Walber de Moura. Curso de direito constitucional. Rio de Janeiro: Forense, 2006.

${ }^{44}$ LENZA, Pedro. Direito constitucional esquematizado. Pedro Lenza. 16. ed. rev., atual. e ampl. São Paulo: Saraiva, 2012.
} 
PIASSA, Felipe José e DIAS, Bruno Smolarek. Influências pós-positivistas ao novo direito constitucional e o fenômeno da constitucionalização do direito. Revista Eletrônica Direito e Política, Programa de Pós-Graduação Stricto Sensu em Ciência Jurídica da UNIVALI, Itajaí, v.10, n.3, $2^{\circ}$ quadrimestre de 2015. Disponível em: www.univali.br/direitoepolitica - ISSN 1980-7791.

E a partir deste cenário pós-positivista floresceu o neoconstitucionalismo, importando em uma nova hermenêutica constitucional e impondo força normativa à norma constitucional. Superou-se o antigo modelo de constituição em que o texto constitucional trazia apenas caráter político.

Por fim, como consequência desse processo, surge o abordado fenômeno conhecido como constitucionalização do direito e a efetividade do próprio direito constitucional, aquele correspondente a uma irradiação dos valores abrigados nos princípios e regras da Constituição por todo o ordenamento jurídico, resultando na aplicação direta da Lei Maior e na interpretação das normas infraconstitucionais conforme a Carta Fundamental.

Depreende-se com fulcro nisso, dentre outras conclusões, que o Direito, a fim de acompanhar as mutações das relações sociais e pessoais, o "derretimento dos sólidos" - traço permanente da modernidade - como diria Bauman, exige mudanças que quase sempre não conseguem ser acompanhadas pelo Legislativo na edição ou reforma de leis e decretos. Daí é que surge a importância da discussão alinhavada, refletida no fundamental papel do Judiciário na interpretação constitucional e das demais normas sob a luz da Lei Fundamental, com vistas a assegurar a melhor prestação jurisdicional e, principalmente, a dignidade da pessoa humana e os direitos fundamentais, elementos basilares do Direito e de observação obrigatória nas relações sociais como um todo, sobretudo quando se vive em um Estado Democrático de Direito ou quando se busca construí-lo.

\section{REFERÊNCIAS DAS FONTES CITADAS}

AGRA, Walber de Moura. Curso de direito constitucional. Rio de Janeiro: Forense, 2006. 
PIASSA, Felipe José e DIAS, Bruno Smolarek. Influências pós-positivistas ao novo direito constitucional e o fenômeno da constitucionalização do direito. Revista Eletrônica Direito e Política, Programa de Pós-Graduação Stricto Sensu em Ciência Jurídica da UNIVALI, Itajaí, v.10, n.3, $2^{\circ}$ quadrimestre de 2015. Disponível em: www.univali.br/direitoepolitica - ISSN 1980-7791.

ALEXY, Robert. Constitucionalismo discursivo. Trad. de Luís Afonso Heck. Porto Alegre: Livraria do Advogado, 2007.

Teoria dos direitos fundamentais. Trad. de: Virgílio Afonso da Silva. São Paulo: Malheiros, 2008. Título original: Theorie der Grundrechte.

BARROSO, Luís Roberto. A Constituição Brasileira de 1988: uma Introdução. In: MARTINS, Ives Granda da Silva; MENDES, Gilmar Ferreira; NASCIMENTO, Carlos Valder do (Coord.). Tratado de Direito Constitucional. v.1. $2^{\text {a }}$ ed.- São Paulo: Saraiva, 2012.

Neoconstitucionalismo e constitucionalização do Direito. 0 triunfo tardio do Direito Constitucional no Brasil. Jus Navigandi, Teresina, ano 10, n. 851, 1 nov. $2005 . \quad$ Disponível em: <http://jus.com.br/artigos/7547>. Acesso em: 1 abr. 2014.

- Fundamentos teóricos e filosóficos do novo Direito Constitucional Brasileiro. Revista de Direito Administrativo. Rio de Janeiro. V. 225. P. 5-37, Jul. -Set. , 2001.

O direito constitucional e a efetividade de suas normas - limites e possibilidades da Constituição brasileira. 7a.ed. Rio de Janeiro: Renovar, 2003.

Curso de Direito Constitucional Contemporâneo: Os conceitos fundamentais e a construção do novo modelo. $2^{a}$ Ed. São Paulo: Saraiva, 2010.

BAUMAN, Zygmunt. Modernidade líquida. Trad. de: Plínio Dentizien, Rio de Janeiro: Jorge Zahar, 2001.

BOBBIO, Norberto. O positivismo jurídico: lições de filosofia do direito. Trad. de: Margio Pugliesi, São Paulo: Icone, 1995.

DINIZ, Maria Helena. Compêndio de introdução à ciência do direito: introdução à teoria geral do direito, à filosofia do direito, à sociologia jurídica e à lógica jurídica. Norma jurídica e aplicação do Direito. 21 . Ed. Ver. e atual. São Paulo: Saraiva, 2010.

HESSE, Konrad. A força normativa da Constituição. Porto Alegre: Sérgio Antonio Fabris, 1991. 
PIASSA, Felipe José e DIAS, Bruno Smolarek. Influências pós-positivistas ao novo direito constitucional e o fenômeno da constitucionalização do direito. Revista Eletrônica Direito e Política, Programa de Pós-Graduação Stricto Sensu em Ciência Jurídica da UNIVALI, Itajaí, v.10, n.3, $2^{\circ}$ quadrimestre de 2015. Disponível em: www.univali.br/direitoepolitica - ISSN 1980-7791.

KELSEN, Hans. Teoria geral do direito e do Estado. 4 ed. Tradução de: Luís Carlos Borges. São Paulo: Martins Fontes, 2005. Título original: General theory of Law and state.

Teoria pura do direito. Trad. de João Batista Machado. São Paulo: Martins Fontes, 1997. Título original: Reine Rechtslehre.

LENZA, Pedro. Direito constitucional esquematizado/Pedro Lenza. 16. ed. rev., atual. e ampl. São Paulo: Saraiva, 2012.

MONTESQUIEU, Charles de Secondat. O espírito das leis: as formas de governo, a divisão dos poderes. Trad. de: Pedro Vieira Mota. São Paulo: Saraiva, 1987;

ZANON JUNIOR, Orlando Luiz. Teoria complexa do Direito. 2013. 439. Tese (Doutorado em Ciência Jurídica). Universidade do Vale do Itajaí - UNIVALI. Itajaí, 2013.

Submetido em: Abril/2015

Aprovado em: Junho/2015 